\title{
The biological activity of retinoic acid in the domestic fowl and the effects of vitamin A deficiency on the chick embryo
}

\author{
By J. N. THOMPSON,* J. McC. HOWELL, G. A. J. PITT \\ AND CATHERINE I. MCLAUGHLIN \\ Departments of Biochemistry and Veterinary Pathology, University of Liverpool \\ (Received $17 \mathfrak{J}$ uly I968-Accepted 21 February 1969)
}

\begin{abstract}
1. Male and female chickens were reared from hatching on vitamin A-free diets, either unsupplemented or containing retinoic acid (vitamin $A$ acid), methyl retinoate or retinyl acetate (vitamin $\mathrm{A}$ acetate). The birds given retinyl acetate grew well and had a normal appearance, but those given the unsupplemented diet died before 4 weeks of age after developing typical signs of avitaminosis A. The birds given retinoic acid or methyl retinoate did not show overt signs of vitamin A deficiency or other abnormalities except for a progressive failure of vision. Minimal histological changes were found in their retinas, and their vision was rapidly restored after feeding with retinyl acetate.

2. The cocks maintained with retinoic acid or methyl retinoate had normal testes and the hens laid eggs at a normal rate, but although their eggs could be obtained fertile the development of the embryo became abnormal after 2 days incubation and it always died. The development of the embryos could be stimulated and sometimes restored to normal by injection of various forms of vitamin $A$ into the eggs before incubation, or by previous administration of retinyl acetate to the hens.

3. It is concluded that feeding retinoic acid as the sole source of vitamin A enables the hen to produce eggs that lack vitamin A but are otherwise normal, thus permitting the demonstration of a hitherto undescribed requirement of the early chick embryo for vitamin $A$.

4. The toxicity of vitamin A derivatives to chick embryos was investigated; injected retinoic acid was found to be extremely toxic.
\end{abstract}

In experiments with rats, retinoic acid (vitamin $\mathrm{A}$ acid) has been shown to replace the corresponding alcohol, retinol (vitamin A), in the prevention of most of the diverse abnormalities which make up the vitamin A deficiency syndrome. The acid maintains growth and general health in rats (Arens \& van Dorp, 1946; Dowling \& Wald, 1960), but even when administered in large amounts it will not maintain reproduction (Thompson, Howell \& Pitt, I964) nor will it serve as a precursor of retinal (vitamin A aldehyde), the prosthetic group of the visual pigments, and thus will not maintain vision (Dowling \& Wald, I960). Female rats maintained with retinoic acid mate with normal males, but invariably resorb their foetuses (Howell, Thompson \& Pitt, 1964), and male rats maintained with retinoic acid have degenerate testes and are sterile (Howell, Thompson \& Pitt, I963). These abnormalities indicate the nature and significance of the involvement of vitamin $A$ in reproduction in the normally nourished animal. The defects can be prevented by small quantities of retinol and they occur, with other systemic abnormalities, in rats made completely deficient in all forms of vitamin A (Mason, 1939). Similar defects of reproduction have been observed in guinea-pigs maintained with retinoic acid (Howell, Thompson \& Pitt, 1967).

It is not possible to associate the inactivity of retinoic acid in reproduction with any known aspect of vitamin A metabolism or biochemistry. A major obstacle is the meagre

* Present address: Department of Poultry Science, Cornell University, Ithaca, New York, I4850. 
and largely conjectural nature of present knowledge of the mode of action of vitamin A at the molecular level, other than in vision. Retinoic acid is, nevertheless, of value in the investigation of reproductive abnormalities resulting from the absence of vitamin A, because it permits these defects to be produced in animals unaffected by other systemic consequences of avitaminosis, such as impaired growth, reduced appetite, epithelial abnormalities, infection and early mortality.

Retinoic acid had earlier been used by Dowling \& Wald (1960) to study in rats the visual role of vitamin $A$. Rats maintained on a vitamin A-free diet supplemented with retinoic acid become depleted of visual pigment (rhodopsin) and have elevated electroretinogram thresholds. The disappearance of the prosthetic group of the visual pigment is followed by the loss of the protein portion, opsin, and degeneration of receptor cells, which can be seen in histological sections of the retina.

Following upon our investigations with rats (Thompson et al. 1964) and guinea-pigs (Howell et al. 1967), experiments were undertaken to test the effect of replacing the vitamin $A$ in the diet of fowl with retinoic acid. The domestic fowl was chosen firstly because of obvious major differences from laboratory rodents in the reproductive system, and secondly because, in contrast with rats and guinea-pigs, the fowl has a retina in which the cones outnumber the rods (Walls, 1942). It was hoped that extension of the tests with retinoic acid to the fowl would reveal information on the role of vitamin $A$ in reproduction in birds, and also demonstrate in the living bird that cone vision involves retinal as a chromophore.

The results obtained on completion of the first experiment with retinoic acid in the fowl were considered to be sufficiently important to justify further investigations; eventually, over a period of 4 years, three experiments were completed in which chicks of both sexes were reared to maturity on semi-synthetic diets free from vitamin $A$ and provitamins A but with supplements of retinoic acid. The results of these experiments, some of which have been briefly described previously (Thompson, Howell, Pitt \& Houghton, 1965$)$, are summarized in this paper.

\section{EXPERIMENTAL AND RESULTS}

\section{Birds, diets and management}

Day-old chicks were reared to maturity on semi-synthetic diets free from carotenoids and preformed vitamin A, but supplemented with either methyl retinoate or free retinoic acid. Some control groups of birds were given the unsupplemented basal diet, or the basal diets supplemented with retinyl acetate. The supplements of retinoic acid, methyl retinoate and retinyl acetate were dissolved in arachis oil and were mixed in the diets at a level of $3 \mu \mathrm{g} / \mathrm{g}$ diet, except where specifically stated.

The chicks used in Expt I were White Leghorn $\times$ Buff Rock; those in Expts 2 and 3 were Thornber 404 strain. Different types of basal diets were used to allow for the nutritional requirements of the birds at each stage of development (see Table I). The first type (brooder diets, B) was given to the chicks until they were 6 weeks old and the second type (rearer diets, R) was given from then onwards. When at the point of lay, the hens were given the third type of diet (laying diets, L). 
Diets $\mathrm{B}_{1}, \mathrm{~B}_{2}, \mathrm{R}_{\mathrm{I}}, \mathrm{R}_{2}, \mathrm{~L}_{\mathrm{I}}$ and $\mathrm{L}_{2}$ were orthodox purified diets in which gelatin and extracted casein were used as sources of protein, and from previous experiments with rats the constituents were known to be free from trace quantities of retinol and its precursors. Diets $R_{3}$ and $L_{3}$ were based on extracted soya-bean meal, which was found by chemical analysis and biological assay to contain negligible quantities of provitamins A.

\section{Table I. Percentage composition of the basal vitamin A-free diets}

\begin{tabular}{|c|c|c|c|c|c|c|c|c|}
\hline & \multicolumn{2}{|c|}{ Brooder diet } & \multicolumn{3}{|c|}{ Rearer diet } & \multicolumn{3}{|c|}{ Laying diet } \\
\hline & $\mathbf{B} \mathbf{~}$ & $\mathrm{B}_{2}$ & $\mathbf{R}_{\mathbf{I}}$ & $\mathrm{R}_{2}$ & $\mathbf{R}_{3}$ & $L_{I}$ & $L_{2}$ & $\mathbf{L}_{3}$ \\
\hline Extracted soya-bean meal & - & - & - & 一 & 40 & - & - & 40 \\
\hline Vitamin-free casein & 20 & 20 & 15 & I5 & - & 15 & 15 & $\longrightarrow$ \\
\hline Gelatin & I5 & I5 & - & IO & 10 & IO & I0 & $一$ \\
\hline Arginine hydrochloride & 0.6 & 0.6 & 0.5 & 0.5 & - & 0.5 & 0.5 & 一 \\
\hline Methionine & 0.6 & 0.6 & 0.5 & 0.5 & 0.5 & 0.5 & 0.5 & 0.5 \\
\hline Glycine & I & $\mathbf{I}$ & - & - & - & - & - & $\longrightarrow$ \\
\hline Arachis oil & 9 & 9 & 4 & 4 & 4 & 4 & 2 & 2 \\
\hline Vitamin supplement in oil* & $\mathbf{I}$ & $\mathbf{I}$ & $\mathbf{I}$ & I & I & $i$ & $\mathbf{I}$ & $\mathbf{I}$ \\
\hline Vitamin supplement in glucose & $\mathbf{I}$ & I & I & I & I & I & $\mathbf{I}$ & I \\
\hline Choline chloride in glucose $f$ & I & $\mathbf{I}$ & I & $\mathbf{I}$ & 一 & $\mathbf{I}$ & $\mathbf{I}$ & 一 \\
\hline Dried brewer's yeast & - & 一 & - & 一 & - & 5 & 5 & 5 \\
\hline Cellulose & 3 & 3 & 3 & 3 & - & 3 & 20 & - \\
\hline Mineral mixture§ & 6 & - & 6 & - & - & - & - & 一 \\
\hline Mineral mixture\|l & - & 6 & - & 6 & 6 & 6 & 6 & 6 \\
\hline $\mathrm{CaCO}_{3}$ & - & - & - & - & - & 2.0 & $4 \cdot 5$ & $4 \cdot 5$ \\
\hline $\mathrm{CaHPO}_{4}$ & 一 & - & - & - & - & - & 0.5 & 0.5 \\
\hline Glucose & $4 I \cdot 8$ & $41 \cdot 8$ & 58 & 58 & $47 \cdot 5$ & $5 I \cdot 0$ & 33.0 & 39.5 \\
\hline
\end{tabular}

* A solution in arachis oil containing $2 \mu \mathrm{g}$ cholecalciferol and $2 \mathrm{mg}$ DL- $\alpha$-tocopheryl acetate per $\mathrm{g}$.

† A mixture triturated in glucose containing per g: cyanocobalamin $3 \mu \mathrm{g}$, biotin $30 \mu \mathrm{g}$, menaphthone $100 \mu \mathrm{g}$, folic acid $400 \mu \mathrm{g}$, pyridoxol hydrochloride $800 \mu \mathrm{g}, p$-aminobenzoic acid $800 \mu \mathrm{g}$, riboflavine I.6 mg, calcium pantothenate $2.0 \mathrm{mg}$, thiamine hydrochloride $2.5 \mathrm{mg}$, nicotinic acid $10 \mathrm{mg}$ and inositol Io mg.

I A mixture of $800 \mathrm{mg}$ glucose and $200 \mathrm{mg}$ choline chloride.

$\S$ Salt mixture of Briggs, Spivey, Keresztesy \& Silverman (I952).

I| Salts $\mathrm{N}$ of Fox \& Briggs (1960) with the following additions to each $60 \mathrm{~kg}: \mathrm{Na}_{2} \mathrm{MoO}_{4} \cdot \mathrm{2}_{2} \mathrm{O}_{5} \mathrm{~g}$, $\mathrm{Na}_{2} \mathrm{SeO}_{3} 200 \mathrm{mg}, \mathrm{NaF} 500 \mathrm{mg}, \mathrm{CoCl}_{2} .6 \mathrm{H}_{2} \mathrm{O} 2 \mathrm{~g}, \mathrm{H}_{3} \mathrm{BO}_{3} \mathrm{I} \circ \mathrm{g}, \mathrm{K}_{2} \mathrm{Al}_{2}\left(\mathrm{SO}_{4}\right)_{4} .24 \mathrm{H}_{2} \mathrm{O} 50 \mathrm{~g}, \mathrm{Na}_{2} \mathrm{SiO}_{3}$. $9 \mathrm{H}_{2} \mathrm{O} 5 \circ \mathrm{g}$.

Chicks were reared to 6 weeks of age in electrically heated brooders and were then transferred to battery fattening cages. From 18 weeks of age the hens were housed individually in battery laying cages and the cocks were kept in threes, pairs, or individually in specially built pens.

The poultry houses were illuminated entirely by artificial light. Throughout Expt I I $5 \mathrm{~h}$ light was provided daily. In Expts 2 and 3 an orthodox lighting programme for rearing laying pullets was arranged: during the first to weeks the daily period of light was reduced gradually from $22 \mathrm{~h}$ to $8 \mathrm{~h}$, and it was kept constant at this level until the birds were 22 weeks old, when the daily period was increased by an average of $30 \mathrm{~min}$ weekly until $\mathrm{I} 8 \mathrm{~h}$ light was provided each day.

Hens were inseminated artificially (Cooper, I963) with $0.2 \mathrm{ml}$ semen. The inseminations were made twice weekly at a time of day which was not more than $4 \mathrm{~h}$ before the lights were extinguished. 


\section{Incubation experiments}

Eggs were collected daily and were usually set in a Curfew electric observation incubator (Curfew Appliances Ltd, Ottershaw, Surrey) on the day of laying.

In many experiments, substances were injected into eggs either dissolved in arachis oil or suspended in saline. Saline suspensions were prepared by diluting, into roo volumes of saline, solutions of the test substance in ethanol containing Tween 80 . The saline had been freshly boiled and cooled to eliminate micro-organisms and also to remove dissolved oxygen which otherwise would have a deleterious effect on vitamin A derivatives. Eggs for injection were cleaned with a swab moistened with ethanol, and then a hole was made in the shell with a dental drill. The test solution ( $(0.1 \mathrm{ml})$ was injected into the albumen away from the embryo, using a hypodermic syringe, the hole being afterwards sealed with a domestic adhesive (Bostik I; Bostik Ltd, Leicester). Most of the injections were made before setting, but in some experiments injections were made after varying periods of incubation, and in these instances holes were drilled and sealed before setting in the usual fashion, and the injections were subsequently made through the adhesive plug, which was then resealed.

\section{Embryological studies}

Eggs were routinely candled after 5 days incubation and those not showing normal development were opened for examination; those remaining were usually allowed to continue incubation until the expected time of hatching. In most of the experiments the early embryos were examined by the naked eye, or with the aid of a binocular dissection microscope. Black ink was injected beneath the embryo to provide a contrasting background. When it was necessary to preserve whole embryos for repeated and more detailed examinations, the embryos and membranes were first fixed on the yolk surface with formol nitric, and then, after removal to a dish of water, with Heidenhain's Susa. After staining with alum cochineal, dehydration in alcohols and clearing in dibutyl phthalate, the specimens were mounted in methyl methacrylate polymer for examination with a low-power microscope.

\section{Retinal histology}

In order to obtain sections of the retina, birds were killed by chloroform inhalation and the eyes immediately removed and fixed in Zenker's fluid. The eyes were later bisected, the lens was removed and each half embedded in low-viscosity nitrocellulose. Sections were cut at $12 \mu \mathrm{m}$ and stained by haematoxylin and eosin. Selected sections were also stained by cresyl violet and by phosphotungstic acid haematoxylin.

\section{Vitamin $A$ derivatives}

Retinoic acid, $\beta$-carotene, $\beta$-apo- $8^{\prime}$-carotenoic acid and ethyl- $\beta$-apo- $8^{\prime}$-carotenoate were provided by F. Hoffmann-La Roche $\&$ Co., Basel. Methyl retinoate was prepared from retinoic acid by the method of Robeson (1952) and methyl-5,6-epoxyretinoate was made by the procedure of Morgan \& Thompson (I966). All these, and other vitamin A compounds used, were crystalline. 


\section{Expts $\mathrm{I}-3:$ procedure and results}

Details of the diets and of the dietary supplements used are shown in Table 2. The results of all three experiments will be considered together.

The chicks given the unsupplemented basal diets (groups I A and $2 \mathrm{~A}$ ) became ataxic and died when between 3 and 4 weeks old. Other signs of vitamin A deficiency included areas of squamous metaplasia in the nasal epithelium and urate deposits in the kidneys and ureters.

Table 2. Chicks used in experiments and their dietary regimes

\begin{tabular}{|c|c|c|c|c|c|c|}
\hline $\begin{array}{l}\text { Expt } \\
\text { no. }\end{array}$ & Strain & Group & $\begin{array}{l}\text { No. of } \\
\text { birds }\end{array}$ & Sex & Basal diets* & Supplement† \\
\hline $\mathbf{I}$ & $\begin{array}{l}\text { White Leghorn } \\
\times \text { Buff Rock }\end{array}$ & $\begin{array}{l}\text { IA } \\
\text { IB } \\
\text { IC } \\
\text { ID }\end{array}$ & $\begin{array}{l}9 \\
13 \\
14 \\
15 \\
13 \\
13 \\
13 \\
13\end{array}$ & $\begin{array}{l}\hat{0} \\
0 \\
0 \\
\hat{0} \\
0 \\
0 \\
0 \\
0 \\
+ \\
0 \\
0 \\
0\end{array}$ & $\begin{array}{l}\mathrm{B}_{\mathbf{I}} \\
\mathrm{BI}_{\mathbf{I}} \\
\mathrm{B}_{\mathbf{I}}, \mathrm{R}_{\mathbf{I}} \\
\mathrm{B}_{\mathbf{I}}, \mathrm{R}_{\mathrm{I}}, \mathrm{L}_{\mathbf{I}} \\
\mathrm{BI}_{\mathbf{I}}, \mathrm{R}_{\mathbf{I}} \\
\mathrm{B}_{\mathbf{I}}, \mathrm{R}_{\mathrm{I}}, \mathrm{L}_{\mathbf{I}} \\
\text { Commercial } \\
\text { Commercial }\end{array}$ & $\begin{array}{l}\text { None } \\
\text { None } \\
\text { Methyl retinoate } \\
\text { Methyl retinoate } \\
\text { Retinyl acetate } \\
\text { Retinyl acetate } \\
\text { None } \\
\text { None }\end{array}$ \\
\hline 2 & Thornber '404' & $\begin{array}{l}2 A \\
2 B\end{array}$ & $\begin{array}{l}75 \\
75 \\
27\end{array}$ & $\begin{array}{l}0 \\
0 \\
+ \\
0\end{array}$ & $\begin{array}{l}\mathrm{B}_{2} \\
\mathrm{~B}_{2}, \mathrm{R}_{2}, \mathrm{~L}_{2} \\
\mathrm{~B}_{2}, \mathrm{R}_{2}\end{array}$ & $\begin{array}{l}\text { None } \\
\text { Retinoic acid } \\
\text { Retinoic acid }\end{array}$ \\
\hline 3 & Thornber ' 404 ' & $3^{B}$ & $\begin{array}{r}64 \\
* \text { See } \\
+3 \mu\end{array}$ & q & $\mathrm{B}_{2}, \mathrm{R}_{3}, \mathrm{~L}_{3}$ & Retinoic acid \\
\hline
\end{tabular}

Table 3. Mean body-weights $(g)$ of chicks (Expt I) at various ages

\begin{tabular}{|c|c|c|c|c|c|c|}
\hline \multirow[b]{2}{*}{ Sex } & \multirow[b]{2}{*}{ Group } & \multirow[b]{2}{*}{ Dietary regime } & \multicolumn{4}{|c|}{ Age } \\
\hline & & & I day & 4 weeks & 8 weeks & I6 weeks \\
\hline \multirow[t]{3}{*}{$0^{*}$} & I $\mathrm{B}$ & Methyl retinoate & 42 & 416 & I I I 9 & 2059 \\
\hline & IC & Retinyl acetate & $4 \mathrm{I}$ & 412 & I 160 & 2327 \\
\hline & ID & Commercial & $4^{I}$ & 321 & 997 & 2204 \\
\hline \multirow[t]{3}{*}{ q } & IB & Methyl retinoate & 40 & 370 & 905 & 1653 \\
\hline & IC & Retinyl acetate & 40 & 396 & 980 & I 789 \\
\hline & I D & Commercial & $4 I$ & 290 & 826 & I 6 I9 \\
\hline
\end{tabular}

The chicks given methyl retinoate (group $x$ B), retinoic acid (groups 2 B and 3 B) and retinyl acetate (group ${ }_{\mathrm{I}} \mathrm{C}$ ) grew rapidly to maturity and did not show any overt signs of vitamin A deficiency. The rapid growth of these birds is indicated by the mean body-weights recorded in Expt I (see Table 3).

Examination of birds given either retinoic acid or methyl retinoate, which were killed at various times during all three experiments, confirmed the normal condition of their internal organs, and the absence of the characteristic epithelial metaplasia of vitamin A deficiency. Spectroscopic examination of the liver non-saponifiable lipid revealed no trace of retinol, indicating that in the fowl, as in the rat, the acid is not reduced to the alcohol or (since the alcohol and aldehyde are readily interconvertible) to the aldehyde. 


\section{Effects on vision}

Hens and cocks maintained with retinoic acid (groups $2 \mathrm{~B}$ and $3 \mathrm{~B}$ ) or methyl retinoate (group I B) were regularly examined for signs of impaired vision. The first indication of a visual defect was an abnormally wide dilatation of the pupils when the birds were placed in dimmer light. By the time the birds were 80 days old the abnormal dilatation of the pupils was detectable even in normal lighting conditions, and by 130 days the behaviour of the birds indicated that they had poor vision even in bright light. After 200 days on the diet the birds seemed to be blind; some behavioural and pupillary response could, however, be elicited with very bright lights-even after 2 years on the experiments.

Blindness had little indirect effect on general health and it did not seriously impair the ability of the birds to find food and water. The affected hens continued to lay at a normal rate (see below) and the cocks possessed all the vigour and aggressiveness of the normally sighted controls given retinyl acetate.

Histological examinations were made of the retinas of cocks in Expt I between I02 and 1122 days of age. No abnormalities were seen in any of the retinas of birds fed with commercial diet (group I D) or retinyl acetate (group IC) (Pl. I $a$ ). In birds maintained on methyl retinoate (group r B), retinas appeared normal at IO2 days of age (two birds) but in two birds killed on days $\mathrm{I} 3 \mathrm{I}$ and $\mathrm{I} 33$ there was some irregularity of the structures in the rod-cone layer; this was not seen in a bird killed at 148 days, but was present in another killed after 155 days. A loss of density and an alteration in the structures of the rod-cone layer were seen in all birds maintained on retinoic acid that were killed after $194,222,370$ and 446 days ( $\mathrm{Pl}$. I $b$ ). No changes were seen in the outer limiting membrane or in the cellular layers of the retina. The changes in the rod-cone layer were more obvious at the periphery of the retina than near the optic nerve; they progressed slowly and were still limited in a bird that had been fed on the diet for II22 days (Pl. I c).

Vision in these birds maintained with retinoic acid was found to be restored after feeding with retinyl acetate. Two hens (from group I B) which had been on the diet supplemented with methyl retinoate for over a year were each given by mouth I $\mathrm{mg}$ retinyl acetate dissolved in oil. Two days after the treatment normal pupillary responses returned and within a week the vision of the birds seemed to be normal. Curative effects were also observed in another two birds given $\mathrm{I} \mathrm{mg}$ 3-dehydroretinol (vitamin $\mathrm{A}_{2}$ ). In similar experiments thirty hens from group $2 \mathrm{~B}$ that had been on the diet supplemented with retinoic acid for 12 months were given supplements of retinyl acetate. The restoration of vision, as judged by pupillary responses to light, was variable and continued over several weeks, but no evidence was found of an irreversible change.

\section{Reproduction in the male}

Male birds in Expt I were killed at various times between 102 and 446 days of age. Normal spermatogenesis was seen in all, whether given a commercial diet (group i Dsix birds examined), retinyl acetate ( $\mathrm{C}$ - - eight birds) or methyl retinoate ( $\mathrm{I}$ B-ten birds) (see Pl. 2a). We saw no evidence of a gross abnormality similar to that invariably 
found in rats and guinea-pigs maintained on retinoic acid (Howell et al. 1963, 1967). Normal quantities of semen containing highly motile spermatozoa were obtained from the cocks fed with methyl retinoate in Expt I (group I B) or retinoic acid in Expt 2 (group $2 \mathrm{~B}$ ). The fertilizing power of the pooled semen from the cocks fed methyl retinoate (group I B) was proved by inseminating four hens reared on a commercial ration ( $O \cdot I \mathrm{ml}$ semen to each hen once weekly). The first Ioo eggs laid subsequently by these hens were incubated and nintety-two proved to be fertile.

In an investigation of the effect of a complete deficiency of vitamin $A$ on the testes of birds, fourteen cocks from group $2 \mathrm{~B}$ after 29 weeks on the experiment were separated into three subgroups and were given the basal diet. Birds in one subgroup (2 BX-four birds) were given supplements of retinoic acid, those in another subgroup ( $2 \mathrm{BY}$-four birds) were given supplements of retinyl acetate and those in the remaining subgroup ( $2 \mathrm{BZ}-$ six birds) were left unsupplemented. The cocks in the unsupplemented subgroup $(2 \mathrm{BZ})$ developed signs of vitamin A deficiency and one died; after 17 days all the remaining birds were killed and examined histologically. In five of the six deficient birds in subgroup $2 \mathrm{BZ}$ the testes were smaller (mean weight $5.6 \mathrm{~g})$ than those from subgroups $2 \mathrm{BX}\left(\mathrm{I} 7^{\circ} \circ \mathrm{g}\right)$ and $2 \mathrm{BY}(\mathrm{I} 6.0 \mathrm{~g})$. The testes of the sixth bird in $2 \mathrm{BZ}$ were enlarged by inflammatory changes and deposited urates. Histological evidence of degeneration of the semeniferous epithelium was clearly present in five birds of subgroup $2 \mathrm{BZ}$ : all tubules had lost spermatids and many were lying in the lumen of the tubules. In the sixth deficient bird spermatids in some tubules had been sloughed into the lumen, indicating that degenerative changes had recently commenced. No abnormalities were observed in the testes of birds in the groups given retinyl acetate or retinoic acid (Pl. 2a).

\section{Reproduction in hens}

Egg production was essentially normal in all surviving groups. All the birds on the purified rations laid eggs with colourless yolks because the diets did not contain significant quantities of xanthophyll pigments. There was a similar noticeable absence of pigment from the beaks and shanks. No evidence was found to suggest that egg production by the hens given retinoic acid or methyl retinoate was in any way inferior to that by the hens given retinyl acetate.

The birds on the casein-gelatin diets in Expts $\mathrm{I}$ and 2 consistently laid eggs which were smaller in size and in weight than those laid by control hens of the same age given a commercial ration. These differences were attributed to unidentified defects in the purified diets which were unrelated to the vitamin A status. In Expt 3, the hens in group 3 B given the soya-bean meal diet laid eggs of normal size and weight.

\section{Fertility and embryonic development}

After regular inseminations with semen from normal cocks, fertility was found to be high in the eggs from the hens given methyl retinoate (group I B) and retinoic acid (groups $2 \mathrm{~B}$ and $3 \mathrm{~B}$ ). Eggs from the control group of hens given retinyl acetate (group IC) were obtained fertile and, although hatchability did not attain normal levels, most of these eggs developed beyond the rst week of incubation. 
Uninjected eggs from the hens given retinoic acid or methyl retinoate (groups $\mathrm{I}$, $2 \mathrm{~B}$ and ${ }_{3} \mathrm{~B}$ ), although fertile, never hatched nor did any develop normally for more than 2 days of incubation. In most of these eggs a characteristic abnormality of development of the embryo was observed and this is described below; the remaining exceptions, which represented a small proportion of the total, consisted of either infertile eggs or eggs in which the embryos died during the first day of incubation. Typically, the embryos examined during the first $48 \mathrm{~h}$ of incubation were found to be normal in appearance but slightly retarded in development when compared with controls. The rate of development during this period in normal eggs varies considerably, and it is therefore impossible, without comparing large numbers of eggs, to establish when the retardation in deficient eggs begins; however by $36 \mathrm{~h}$ the deficient eggs were consistently less mature than controls. The affected embryos eventually reached a stage of development similar to that attained by normal embryos after about $48 \mathrm{~h}$ (i.e. stage $\mathrm{I} 3$ of Hamburger \& Hamilton, 195I). At this stage in normal eggs the circulatory system in the area vasculosa shows signs of a marked increase in activity and the uniform network of capillaries surrounding the embryo is rapidly transformed into well-defined arteries and veins. In the eggs from hens fed retinoic acid the development of the embryos invariably failed to continue beyond stage ${ }_{3} 3$ and some died earlier. The expansion of the area vasculosa usually continued, but there was never an active circulation of any magnitude nor did major vessels form.

Examination of over a thousand unfixed and unstained embryos from eggs of hens maintained with retinoic acid or methyl retinoate after 5 days incubation consistently confirmed that development had been arrested at about the $48 \mathrm{~h}$ stage. To supplement these observations on the early changes, eggs were opened after varying periods of incubation and the embryos were examined, after fixing and staining, under a lowpower microscope. The eggs for this experiment were obtained from the hens given the soya-bean meal diet and retinoic acid (group $3 \mathrm{~B}$ ), as the soya-bean meal basal diet was considered to be nutritionally the most satisfactory and thus the diet least likely to introduce complications due to dietary deficiencies unrelated to the vitamin $A$ status. Eggs for a control group of embryos were obtained from a few hens taken from the same group $\left({ }_{3} \mathrm{~B}\right)$ and given supplements of I $\mathrm{mg}$ retinyl acetate per hen per day until the end of the experiment; the hatchability of such eggs was quite good-see, for example, subgroup $3 \mathrm{BN}$ in Table 10.

Eggs were removed from the incubators after $36,42,54$ and $66 \mathrm{~h}$, and the embryos with membranes were fixed and stained for examination. The embryos from individual fertile eggs were classified in stages (see Table 4) according to the scheme of Hamburger \& Hamilton (195 1 ). The embryos from the control group of eggs appeared normal at all stages (see Table 4), confirming other experiments to be described below, which suggest that the abnormality of embryonic development in the eggs from the unsupplemented hens is due to a deficiency of vitamin A. No abnormality was apparent in the eggs from the untreated group after $3^{6}$ and $4^{2} \mathrm{~h}$ incubation, and the developmental stages attained by the embryos were not markedly different from normal. However, at $48 \mathrm{~h}$, the embryos in the eggs from the unsupplemented hens were beginning to show signs of aberrant development: the over-all elongation of the trunk was 
retarded, and somites were noticeably crowded, particularly in the anterior region where they appeared to be compressing the hind-brain. Embryos in all the eggs from this group of hens examined at 54 and $66 \mathrm{~h}$ were abnormal.

Although abnormalities were first detected in the 'deficient' group after $48 \mathrm{~h}$ incubation, some aspects of normal development had continued in eggs incubated for longer periods: the malformed embryo head sometimes rotated, the number of somites increased, and often clear indications of limb buds could eventually be discerned. The area vasculosa expanded and the heart (which regularly was found to be beating, albeit

\section{Table 4. Development of embryos in eggs from hens reared on vitamin $A$-deficient diet supplemented with retinoic acid (group $3 B$ )} (Embryos were classified in stages according to Hamburger \& Hamilton ( $195 \mathrm{I}$ ). Those marked
with an asterisk showed evidence of abnormality. Normal progress of development is shown by
the embryos in eggs from hens taken from group $3^{B}$ and given retinyl acetate)

\begin{tabular}{|c|c|c|c|c|c|c|c|c|c|c|c|c|}
\hline \multirow[b]{2}{*}{ Diet of hen } & \multirow{2}{*}{$\begin{array}{c}\text { Time of } \\
\text { incubation } \\
\text { (h) }\end{array}$} & \multicolumn{11}{|c|}{ No. of embryos at stage: } \\
\hline & & 6 & 7 & 8 & 9 & IO & II & 12 & 13 & 14 & 15 & 16 \\
\hline Basal & 36 & 2 & $\mathbf{I}$ & 9 & $\mathbf{I}$ & $\mathbf{I}$ & - & - & - & - & - & 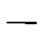 \\
\hline+ retiny & 36 & - & - & 2 & 5 & - & 一 & - & - & 一 & - & 一 \\
\hline Basa & 42 & - & $\mathbf{I}$ & 3 & I I & 7 & 2 & 2 & - & - & - & - \\
\hline Basal + retiny & 42 & - & I & $\mathbf{I}$ & 5 & 13 & 8 & - & - & - & - & - \\
\hline Basa & 48 & - & - & - & I & 8 & I $5 *$ & 8* & $6 *$ & - & $\longrightarrow$ & 一 \\
\hline Basal + retinyl acetate & 48 & - & - & - & $\mathbf{I}$ & 一 & 4 & I I & 4 & - & - & 一 \\
\hline Basal & 54 & - & - & - & - & - & - & $5^{*}$ & $34 *$ & 一 & - & - \\
\hline etinyl acetate & 54 & - & - & - & - & - & - & 3 & 7 & $\mathbf{I}$ & - & - \\
\hline Bas & 66 & - & 一 & 一 & - & - & - & - & $(24$ & abr & Lorme & 1) \\
\hline Basal + retinyl acetate & 66 & - & - & - & - & - & - & - & - & - & - & 16 \\
\hline
\end{tabular}

slowly, on first opening the eggs) accumulated more blood. There was never, however, any evidence of large-sized blood vessels spanning the network of capillaries in the area pellucida, and the circulatory system in the embryo, if in existence, received blood from the extra-embryonic blood islands and the sinus terminalis only by what appeared to be a slow, passive drainage. After several days' incubation the grossly malformed embryos disintegrated. There remained a large expanding area vasculosa, and at its perimeter the sinus terminalis, which, in accumulating much of the blood from the blood islands, gave the eggs a characteristic 'blood ring' appearance when candled.

\section{Effect of vitamin $A$ derivatives on embryonic development}

A possible explanation of the death of the embryos, in the eggs from the hens maintained with retinoic acid or methyl retinoate, was that retinoic acid and its ester were unable to meet an hitherto undescribed requirement of the early embryo for vitamin $A$. This effect could have been due either to inherent inability of the acid to function in some essential role in the embryo, or to the failure of the hen to deposit retinoic acid or its ester in the egg. To test these possibilities, vitamin A-active substances were injected into the eggs before incubation, and the effects on the subsequent development of the embryo were observed.

In some cases, solutions of the substances in oil (0.5 or I $\mathrm{mg}$ in $0.1 \mathrm{ml}$ ) were injected, 
and thus it was demonstrated that retinol, retinal and retinyl acetate would maintain embryonic development in the eggs from hens maintained with methyl retinoate (group I B). The eggs were candled after 5 days incubation; those developing normally were returned to the incubators, and the remainder were opened and examined. The results (Table 5) indicated that many of the fertile injected eggs were stimulated to develop normally to 5 days and some even to hatching.

\section{Table 5. Effect of vitamin A derivatives on development of embryos in eggs from hens maintained with methyl retinoate (group $\mathrm{I} B$ )}

(The eggs were injected once before incubation with $500 \mu \mathrm{g}$ or $250 \mu \mathrm{g}$ of the derivatives dissolved in $\sigma^{\circ} \mathrm{Iml}$ arachis oil. After candling at 5 days the eggs not developing normally were examined and classified as (A) infertile or very early death of embryo; (B) dead embryo at about stage I3) $_{3}$

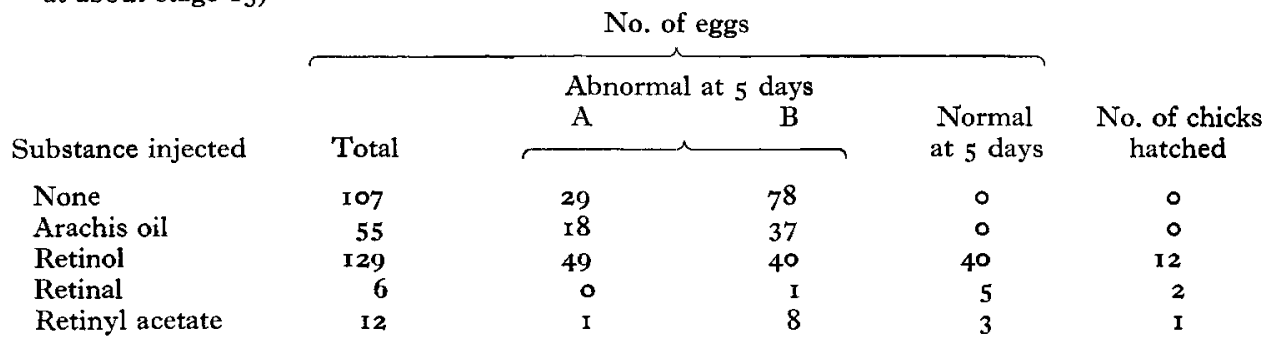

In more extensive tests with eggs from hens maintained with retinoic acid (group 2B) the embryos were classified after 5 days incubation into five categories. Three of these included stages of development which might be attained in untreated eggs, i.e. the eggs were infertile (category I), the embryos had died at very early stages (II), or they had died after about $48 \mathrm{~h}$ incubation (III). The remaining categories included only embryos that had developed beyond the stages at which those in untreated eggs would have become abnormal. Thus these eggs either contained normal embryos (V) or embryos which had developed far enough to stimulate the formation of prominent major blood vessels in the area vasculosa (IV). From the numbers of eggs in each of these categories after a particular treatment, the percentage stimulation of fertile eggs was calculated from

$$
\frac{\text { number of embryos classified IV }+V}{\text { number of embryos classified II }+I I I+I V+V} \times 100 .
$$

The results of some of these experiments, in which eggs were injected once before incubation with saline suspensions of various test substances, are summarized in Table 6. Besides those detailed in Table 2, other nutrients such as phylloquinone, folic acid, cyanocobalamin and biotin were also injected into these eggs, but these substances did not stimulate development of the embryo. In all, $25 \mathrm{I} 8$ eggs were used with an overall fertility of $81 \%$. Of 876 eggs that were either untreated or were injected with materials with no vitamin A activity, none showed signs of embryonic development beyond that observed previously in uninjected eggs from hens maintained with retinoic acid. Injections of free retinoic acid had only a slight stimulating effect (groups 4-7), whereas the activity of its methyl ester (groups 8-12) approached that 
Table 6. Effect of vitamin $A$ derivatives on the development of embryos in eggs from hens maintained with retinoic acid (group $2 B$ )

(Eggs were injected with suspensions of the test substances in $0.1 \mathrm{ml}$ saline and the embryos were examined and classified according to the stage of development after 5 days of incubation)

\begin{tabular}{|c|c|c|c|c|c|c|c|c|c|}
\hline \multirow[b]{3}{*}{ Group } & \multicolumn{2}{|l|}{ Injection } & \multirow{3}{*}{$\begin{array}{c}\text { No. of } \\
\text { eggs }\end{array}$} & \multirow{2}{*}{\multicolumn{2}{|c|}{ No. of embryos, }} & \multirow{2}{*}{\multicolumn{3}{|c|}{ after 5 days, in category: }} & \multirow{3}{*}{$\begin{array}{c}\% \text { fertile } \\
\text { eggs } \\
\text { stimulated } \\
\text { (see p. } 480 \text { ) }\end{array}$} \\
\hline & \multirow[b]{2}{*}{ Substance } & \multirow{2}{*}{$\begin{array}{l}\text { Quan- } \\
\text { tity } \\
(\mu \mathrm{g} / \mathrm{egg})\end{array}$} & & & & & & & \\
\hline & & & & I & II & III & IV & $\mathrm{V}$ & \\
\hline $\mathbf{I}$ & Untreated & - & 560 & 90 & 40 & $43^{\circ}$ & o & $\circ$ & 0 \\
\hline 2 & Saline & - & 140 & 20 & 12 & 108 & 0 & 0 & 0 \\
\hline 3 & Lutein & 100 & 63 & 17 & 5 & $4 \mathrm{I}$ & 0 & 0 & 0 \\
\hline 4 & Retinoic acid & 0.2 & 49 & 3 & 7 & $3^{8}$ & $\mathbf{I}$ & 0 & 2 \\
\hline 5 & Retinoic acid & 0.5 & 68 & 26 & 12 & 29 & 0 & I & 2 \\
\hline 6 & Retinoic acid & $\mathbf{I}$ & 103 & 30 & 42 & 29 & 2 & 0 & 3 \\
\hline 7 & Retinoic acid & 2 & 78 & 8 & 23 & $3^{6}$ & I & 0 & 2 \\
\hline 8 & Methyl retinoate & 2 & 49 & 9 & 7 & 15 & 9 & 9 & 45 \\
\hline 9 & Methyl retinoate & 4 & I 8 & 9 & 3 & 3 & $I$ & 2 & 33 \\
\hline 10 & Methyl retinoate & 10 & 78 & IO & $3^{6}$ & I I & 3 & 18 & $3 I$ \\
\hline I I & Methyl retinoate & 50 & 102 & 17 & 37 & I5 & 9 & 24 & 39 \\
\hline 12 & Methyl retinoate & 100 & 256 & 60 & 104 & 53 & I3 & 26 & 20 \\
\hline 13 & Retinol & 0.1 & 29 & 4 & 3 & 20 & 0 & 2 & 8 \\
\hline 14 & Retinol & 0.5 & 33 & 3 & 0 & 12 & 6 & 12 & 60 \\
\hline 15 & Retinol & 2 & 164 & 29 & II & 24 & 14 & 86 & 74 \\
\hline 16 & Retinol & 20 & $5 I$ & 16 & 6 & 17 & 2 & 10 & 34 \\
\hline I7 & Retinal & 2 & 33 & 5 & 4 & 12 & 3 & 9 & 43 \\
\hline I 8 & Retinal & 4 & 32 & I0 & 5 & 7 & 2 & 8 & 45 \\
\hline I 9 & Retinal & 50 & 34 & 7 & 8 & 4 & 8 & 7 & 56 \\
\hline 20 & Retinal & 100 & 130 & 19 & 32 & 43 & 12 & 24 & 32 \\
\hline $2 I$ & Retinyl acetate & 20 & 50 & 14 & 4 & 23 & 3 & 6 & 25 \\
\hline 22 & $\begin{array}{l}\text { Methyl 5,6- } \\
\text { epoxyretinoate }\end{array}$ & 2 & 128 & 34 & 9 & 54 & I9 & 12 & 33 \\
\hline 23 & $\begin{array}{l}\text { Methyl 5,6- } \\
\text { epoxyretinoate }\end{array}$ & 20 & $3^{6}$ & 13 & 5 & 6 & 2 & 10 & 52 \\
\hline 24 & $\beta$-carotene & 100 & 121 & 9 & 20 & 78 & 7 & 7 & $x_{3}$ \\
\hline
\end{tabular}

* I, infertile; II, very early death of embryo; III, died at about $48 \mathrm{~h}$; IV, major blood vessels developed; V, normal.

Table 7. Effect of injecting retinol at varying times into eggs from hens maintained on retinoic acid (group $2 B$ )

$\begin{array}{ccc}\begin{array}{c}\text { Period of incu- } \\ \text { bation before } \\ \text { injection (h) }\end{array} & \begin{array}{c}\text { No. of eggs } \\ \text { injected }\end{array} & \begin{array}{c}\% \text { fertile eggs } \\ \text { containing em- } \\ \text { bryos developed } \\ \text { beyond } \\ \text { stage } 13\end{array} \\ 0 & 164 & 74 \\ 7 & 37 & 56 \\ 18 & 71 & 48 \\ 29 & 61 & 46 \\ 36 & 29 & 35 \\ 41 & 26 & 19 \\ 44 & 32 & 4 \\ 51 & 25 & \\ 89 & 36 & 0\end{array}$


of retinol (groups 13-16). The latter two substances had their optimal effect when $2 \mu \mathrm{g}$ were administered to each egg before incubation.

Retinal (groups 17-20), retinyl acetate (group 21), methyl 5,6-epoxyretinoate (groups 22-23) and $\beta$-carotene (group 24) also stimulated development.

Injections of retinol were effective even if incubation had proceeded for some time; results demonstrating this effect are shown in Table 7 . Groups of eggs were injected with $2 \mu \mathrm{g}$ retinol in saline after varying periods of pre-incubation and the eggs were examined after a total of 5 days incubation. The results indicate that although stimulation of development is possible during the first 2 days of incubation, it becomes less probable as the period of pre-incubation increases.

\section{Toxic effect of retinoic acid on normal embryos}

When injections of free retinoic acid were made into eggs to test if it was as effective as the true vitamin in maintaining embryonic development it was discovered that the substance was extremely toxic to the chick embryos. Thus single injections containing more than I $\mu \mathrm{g}$ retinoic acid had a deleterious effect on embryos, irrespective of

\section{Table 8. Toxicity to embryos of vitamin A derivatives injected in oil solution into normal eggs}

\begin{tabular}{|c|c|c|c|c|c|}
\hline \multirow{2}{*}{\multicolumn{2}{|c|}{ Injection }} & \multirow[b]{3}{*}{$\begin{array}{l}\text { No. of eggs } \\
\text { injected }\end{array}$} & \multicolumn{3}{|c|}{$\begin{array}{l}\text { No. of embryos classified, after } \\
5 \text { days incubation, as: }\end{array}$} \\
\hline & & & & & \\
\hline Substance & $\begin{array}{l}\text { Quantity } \\
(\mu \mathrm{g} / \mathrm{egg})\end{array}$ & & $\begin{array}{l}\text { early death } \\
\text { of embryo }\end{array}$ & $\begin{array}{l}\text { Dead } \\
\text { embryo }\end{array}$ & Normal \\
\hline None & - & 44 & II & $\mathbf{r}$ & 32 \\
\hline Oil & - & 45 & 17 & 3 & 25 \\
\hline Retinoic acid & $20-500$ & 75 & 75 & 0 & 0 \\
\hline Retinoic acid & IO & 30 & 28 & 2 & 0 \\
\hline Retinoic acid & 5 & I 5 & I 4 & $\mathbf{I}$ & ० \\
\hline Retinoic acid & $2 \cdot 5$ & 30 & $2 I$ & 5 & 4 \\
\hline Retinoic acid & $1 \cdot 0$ & I 5 & 8 & 2 & 5 \\
\hline Retinoic acid & 0.5 & 15 & 6 & $\circ$ & 9 \\
\hline Retinoic acid & $0 \cdot 1$ & 15 & 2 & $\mathbf{I}$ & 12 \\
\hline Retinol & 1000 & 15 & I3 & $I$ & I \\
\hline Retinol & 500 & 15 & 2 & 0 & $\mathbf{I}_{3}$ \\
\hline Retinol & 250 & I 5 & 5 & 0 & IO \\
\hline Methyl retinoate & 2 & I5 & 3 & $\mathbf{I}$ & II \\
\hline Methyl retinoate & 5 & I 5 & 2 & I & I2 \\
\hline Methyl retinoate & 25 & 15 & 4 & 2 & 9 \\
\hline
\end{tabular}

whether the eggs were from hens fed normal diets or from hens fed purified diets containing retinoic acid. In Table 8 are summarized the results of testing the toxic effects of oil solutions of retinoic acid in normal eggs obtained from a commercial breeding flock. The eggs were injected immediately before incubation and were examined 5 days later. Amounts of acid between I $\mu \mathrm{g}$ and $5 \mu \mathrm{g}$ resulted in dead embryos at 5 days which, with their membranes, appeared to be disintegrating. Larger quantities of the acid often caused almost complete dissolution of the blastoderm, leaving only a few caseous streaks on the yolk surface as evidence of development. 
Retinol had a similar toxic effect, but it was necessary to administer more than $500 \mu \mathrm{g}$ in oil solution to each egg to demonstrate this.

The methyl ester of retinoic acid in oil solution was injected in amounts up to $25 \mu \mathrm{g}$ per egg with no toxic effects on the early development of the embryo.

Similar results were obtained when the vitamin A derivatives were administered in saline suspensions. Table 9 compares the toxicity of retinoic acid with that of methyl retinoate, $\beta$-apo-8'-carotenoic acid and ethyl $\beta$-apo-8'-carotenoate. The latter three substances did not have the toxic effects of free retinoic acid.

\section{Table 9. Toxicity to embryos of vitamin $A$ derivatives injected in saline suspension into normal eggs}

\begin{tabular}{|c|c|c|c|c|c|}
\hline Injection & \multirow[b]{2}{*}{$\begin{array}{l}\text { Quantity } \\
(\mu \mathrm{g} / \mathrm{egg})\end{array}$} & \multirow[b]{2}{*}{$\begin{array}{l}\text { No. of eggs } \\
\text { injected }\end{array}$} & \multicolumn{3}{|c|}{$\begin{array}{l}\text { No. of embryos classified, after } \\
5 \text { days incubation, as: }\end{array}$} \\
\hline Substance & & & $\begin{array}{l}\text { Infertile or } \\
\text { early death } \\
\text { of embryo }\end{array}$ & $\begin{array}{l}\text { Dead } \\
\text { embryo }\end{array}$ & Normal \\
\hline Saline + Tween 80 alone & - & 20 & 2 & $\circ$ & I8 \\
\hline Retinoic acid & I & 15 & IO & 2 & 3 \\
\hline Retinoic acid & 5 & 15 & I 5 & o & 0 \\
\hline Methyl retinoate & 4 & 10 & $\mathbf{I}$ & $\circ$ & 9 \\
\hline Methyl retinoate & 8 & Io & 3 & $\circ$ & 7 \\
\hline Methyl retinoate & 16 & 10 & I & 4 & 5 \\
\hline Methyl retinoate & 32 & 10 & 4 & 5 & I \\
\hline Methyl retinoate & 64 & Io & 4 & 2 & 4 \\
\hline$\beta$-apo- $8^{\prime}$-carotenoic acid & 2 & 10 & $\circ$ & $\circ$ & Io \\
\hline$\beta$-apo-8'-carotenoic acid & 10 & Io & $\mathbf{I}$ & $\circ$ & 9 \\
\hline$\beta$-apo-8'-carotenoic acid & IOO & Io & $\circ$ & 0 & ro \\
\hline $\begin{array}{l}\text { Ethyl } \beta \text {-apo- } 8 \\
\text { carotenoate }\end{array}$ & 2 & IO & I & $\circ$ & 9 \\
\hline $\begin{array}{l}\text { Ethyl } \beta \text {-apo- } 8^{\prime}- \\
\text { carotenoate }\end{array}$ & Io & IO & 3 & 0 & 7 \\
\hline $\begin{array}{l}\text { Ethyl } \beta \text {-apo- } 8^{\prime}- \\
\text { carotenoate }\end{array}$ & 100 & Io & 3 & I & 6 \\
\hline
\end{tabular}

\section{Embryonic development in eggs from hens given graded levels of retinyl acetate}

Four subgroups ( $3 \mathrm{BK}, 3 \mathrm{BL}, 3 \mathrm{BM}, 3 \mathrm{BN}$ ), each of five hens, were selected from group $3 \mathrm{~B}$ reared on the soya-bean meal basal diet containing retinoic acid. Each of the hens was given daily a gelatin capsule containing o (subgroup $3 \mathrm{BK}$ ), $10 \mu \mathrm{g}\left({ }_{3} \mathrm{BL}\right.$ ), $50 \mu \mathrm{g}\left({ }_{3} \mathrm{BM}\right)$ or $\mathrm{I} \mathrm{mg}(3 \mathrm{BN})$ retinyl acetate. Eggs produced were incubated until hatching or until the death of the embryo, and the stage of development reached by each embryo was recorded. The observations on embryonic development were started a week before the first dose of retinyl acetate was given to the hens and were continued for 6 weeks. The results are summarized in Table ro. The hens given I mg retinyl acetate $(3 \mathrm{BN})$ laid eggs of high hatchability during the first week of dosing. Eggs from the hens given $5 \circ \mu \mathrm{g}(3 \mathrm{BM})$ reached, although more slowly, the same level of hatchability. A daily dose of ro $\mu \mathrm{g}$ retinyl acetate to the hens of subgroup $3 \mathrm{BL}$ was insufficient to allow any eggs to hatch, but significantly stimulated the development of the embryo beyond the state at which development always stopped in the eggs from unsupplemented hens (subgroup $3 \mathrm{BK}$ ). 


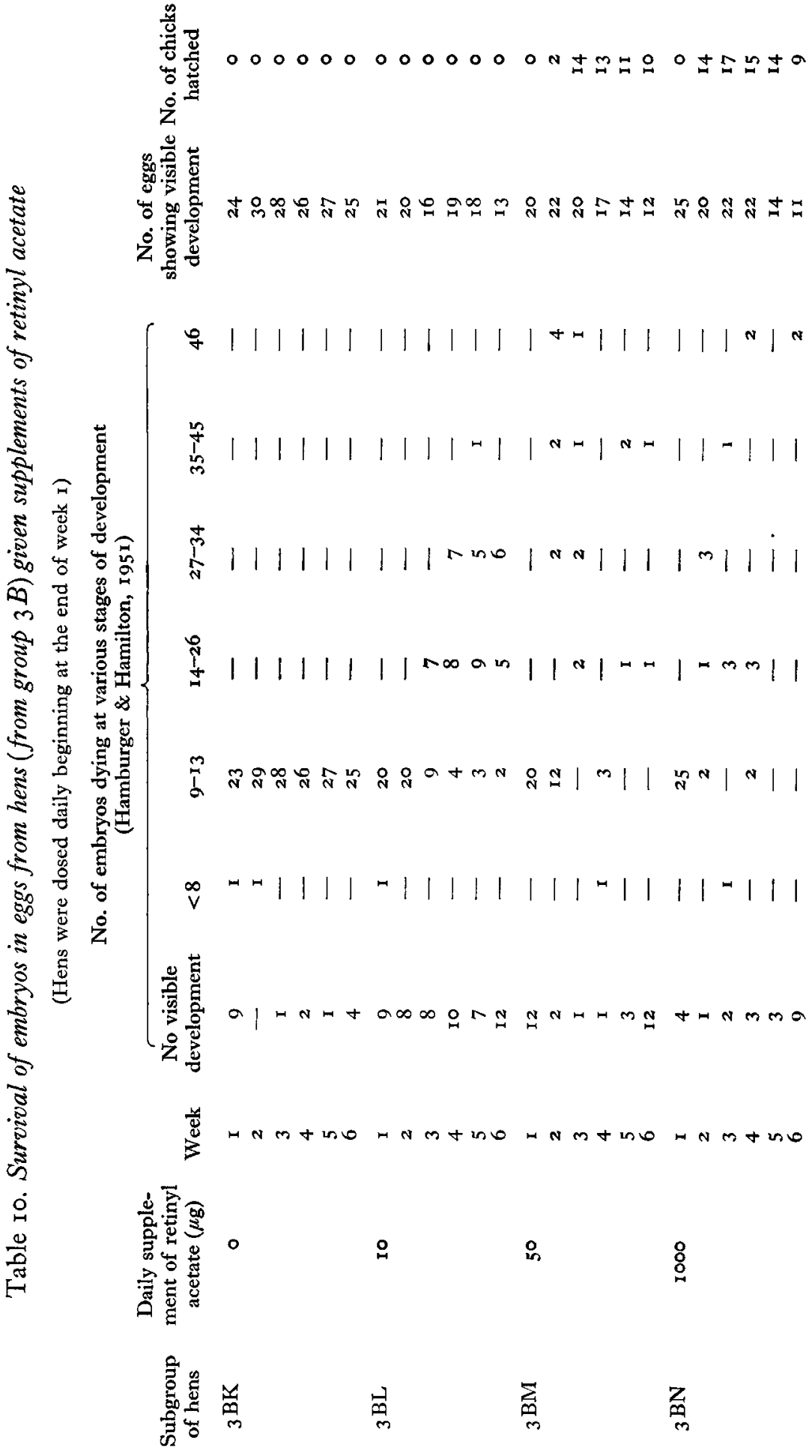




\section{DISCUSSION}

Since the first demonstration of a vitamin A requirement in poultry (Emmett \& Peacock, 1923) there have been many investigations of the effects of vitamin A deficiency on chicks and adult birds. When chicks are given from hatching a diet free from vitamin $\mathrm{A}$ and its precursors, the carotenoid provitamins, they develop ataxia (Wolbach \& Hegsted, I952; Howell \& Thompson, I965), kidney lesions and urate deposits in the viscera (Elvehjem \& Neu, 1932; Hart, Steenbock, Lepkovsky \& Halpin, 1924) and eventually they die. Histological studies have revealed epithelial abnormalities (Seifried, 1930; Jungherr, 1943; Howell \& Thompson, $1967 a$ ) and an overgrowth of periosteal bone (Howell \& Thompson, I967a). Adult fowl made deficient in vitamin A also become ataxic and develop epithelial lesions (Almquist \& Mecchi, 1939; Lowe, Morton, Cunningham \& Vernon, I957; Howell \& Thompson, 1967b) and, as demonstrated recently (Howell \& Thompson, 1967b), an abnormal overgrowth of periosteum.

An early consequence of vitamin A deficiency in adult birds is a rapid fall in egg production. The cessation of laying by deficient hens, which is dramatic evidence of a role of vitamin $\mathrm{A}$ in egg formation, has obscured the effects of deficiency on hatchability. There have, however, been many apparently successful demonstrations of effects of vitamin A deficiency and vitamin A supplementation on hatchability (Landauer, I96I). As critical reviews by Rubin \& Bird (1942) and McClymont \& Hart (I948) indicate, doubt exists as to the significance of many of these experiments. McClymont \& Hart (1948) state: 'Apparently enough vitamin A for complete embryonic development and hatching, if it is required at all for these purposes, is stored in the eggs while there is a sufficient vitamin A reserve in the body of the hen to maintain any egg production at all.'

There have been comparatively few investigations of the effect of vitamin A deficiency on the testes in poultry. Several reports (Wagener \& Harms, I943; Schumacher, Scott, Hughes \& Peterson, 1944; Bohren, Carrick \& Andrews, I945; Ferrand \& Bohren, 1948) suggest that vitamin A deficiency does not affect the reproductive performance of cocks, whereas others claim there is degeneration or underdevelopment of the testes (Seifried \& Köcher, I943; Lowe et al. 1957).

Our investigations of the role of vitamin $A$ in poultry nutrition differ from previous work in that we have used diets supplemented with retinoic acid. It was found that methyl retinoate and retinoic acid maintain growth and general health in the domestic fowl, and prevent overt signs of vitamin A deficiency, namely poor growth, ataxia, epithelial metaplasia, kidney lesions and arrest of egg production. These observations on poultry, which agree with those of Krishnamurthy, Bieri \& Andrews (I963) and de Man, van Leeuven \& Roborgh (I964), extend previous tests of the growth-promoting and vitamin A-like properties of retinoic acid in rats (Arens \& van Dorp, I 946; Dowling \& Wald, 1960; Thompson et al. 1964), guinea-pigs (Howell et al. 1967) and hamsters (unpublished observations).

Investigation of the vitamin $A$ activity of retinoic acid in rats has revealed that although the acid has growth-promoting activity it is not converted in vivo into the true vitamin, retinol. This conclusion was supported by the failure to detect retinol in the 
livers of animals fed substantial quantities of retinoic acid. Furthermore, the ready interconversion of retinol and the corresponding aldehyde, retinal (Glover, Goodwin \& Morton, 1948) indicated that retinoic acid could not act as a precursor of the aldehyde, which has been identified as the prosthetic group of the visual pigments. The deduction that retinoic acid would not maintain vision (Arens \& van Dorp, I949; Moore, r953) was confirmed in the rat by electroretinogram measurements (Dowling $\&$ Wald, 1960 ). It was also discovered that in the rats maintained with retinoic acid the failure of vision was accompanied by irreversible histological changes in the eye. In the rat the expected depletion of the visual pigment chromophore, retinal, was followed by an unexpected loss of the protein moiety, opsin, and eventually degeneration of the receptor cells and histological changes in the retina; the histological lesion at the onset of these changes consisted of a reduction in the number of rod outer segments, but as the degeneration continued there was loss of inner segments and eventually of visual cell nuclei. Dowling \& Wald (1960) explained the breakdown of visual receptor structures in terms of a concept that the constituents were stabilized by each other and their over-all integrity thus depended on the presence of the retinal molecule. The disappearance of visual pigment is an inevitable consequence of an insufficiency of the chromophore, retinal, but our observations on poultry and other animals suggest that the reason for the subsequent loss of the protein moiety, opsin, in the rat, and the breakdown of the visual cells is less obvious. Histological abnormalities were not found in the retinas of guinea-pigs maintained for long periods on vitamin A-deficient diets containing retinoic acid (Howell et al. 1967), nor was marked histological degeneration found in the retinas of our birds in the present experiments. The anatomical changes in the rat retinas are thus more of an enigma than an indication of the general rule implied in the discussion by Dowling \& Wald (1960).

Although our birds maintained with retinoic acid and methyl retinoate did not develop the severe histological changes in the retina which were typical in rats, we did find evidence of histological abnormality in poultry in that there was a loss of density in the receptor outer segment layers. This change was minimal, however, even in a bird which had been on the experiment for over 3 years. The most prominent change in the vision of our birds was gradual, but eventually major, functional impairment occurred as demonstrated by eye pupil dilatation in bright light and by behaviour. The almost complete lack of response to light which eventually characterized the birds maintained with retinoic acid, and the restoration of vision following the administration of retinol, demonstrated unequivocally a major role of vitamin $\mathrm{A}$ in vision in poultry. Our results thus provide direct support for the concept of a retinal-containing visual pigment (iodopsin) as the basis of cone vision in birds (Wald, Brown \& Smith, I954-5).

We noted that supplements of 3 -dehydroretinol also restored vision in birds, although it was not established that this was due to replacement of the normal visual pigment by a new pigment containing 3-dehydroretinal (Wald, Brown \& Smith, 1953).

The ability of retinoic acid to maintain spermatogenesis in cocks reared on retinolfree diets was indicated by the histological appearance of the testes of our birds and by the fertilizing power of their semen. The normal reproductive tissues in cocks 
maintained with methyl retinoate or retinoic acid contrast with the degenerate seminiferous tubules in rats (Howell et al. 1963) and guinea-pigs (Howell et al. 1967) maintained on similar regimes, and it must be concluded that the fowl testis is unlike that of the other two species and probably of mammals in general, in that it does not have a requirement which cannot be met by retinoic acid (Thompson, Howell \& Pitt, 1965). The difference could be due either to an ability of the cock to utilize retinoic acid in an aspect of spermatogenesis that in other animals requires retinol specifically, or to the absence in the fowl of this requirement for vitamin $A$ in the germinal epithelium. In the absence of conclusive evidence to indicate the contrary, we prefer the hypothesis that the fowl differs from other animals in its ability to utilize various forms of vitamin A rather than that it does not employ the vitamin in spermatogenesis.

It was demonstrated in our experiments, as in those of previous workers (Seifried \& Köcher, I943; Lowe et al. I957), that a complete deficiency of vitamin A has a harmful effect on the germinal epithelium in cocks. In animals deprived of all forms of vitamin $\mathrm{A}$ it is difficult to distinguish the direct effects of a lack of the vitamin from the non-specific changes which accompany inanition and general debility. The harmful effect of vitamin A deficiency on the testis in birds is therefore not conclusive evidence of a direct role of vitamin $\mathrm{A}$ in spermatogenesis.

In our hens reared on retinol-free diets containing methyl retinoate or retinoic acid, egg production and fertility were normal. It is well known that egg production requires an adequate provision of vitamin A (Moore, 1957) and the ability of hens to maintain normal rates of laying demonstrates that retinoic acid is able to replace retinol in this aspect of reproduction. There is no evidence that vitamin A deficiency directly affects the formation of fertilizable eggs in any species so far investigated, so the finding that our hens laid fertile eggs was expected.

When these eggs were incubated the embryos failed to develop beyond stage 13 of Hamburger \& Hamilton ( $195 \mathrm{I}$ ), and some failed to reach even this stage. This curious abnormality in embryonic development did not occur in eggs from the control birds given retinyl acetate or in eggs from birds given normal diets. That it was due to a lack of vitamin A was confirmed firstly be injecting retinol and other forms of vitamin A into the eggs before incubation, when in most instances there was stimulation of embryonic development, and secondly, by feeding retinyl acetate to the hens, which completely restored the hatchability of their eggs. During experiments in which substances were injected into eggs before incubation, it was discovered that retinoic acid was exceptional among vitamin A-active substances in its toxicity to embryos. As the appearance of the embryos killed with retinoic acid was unlike that of the embryos in the eggs of the hens maintained with retinoic acid, it is unlikely that the abnormalities in the latter were due to penetration of toxic quantities of retinoic acid into the eggs before laying. Such a mechanism would not be compatible with the beneficial effect of retinol, retinal and retinyl acetate when injected into the eggs, unless antagonistic effects, which we have been unable to demonstrate, are postulated. More direct evidence against this possibility was obtained in the experiments in which we showed (Table 6) that retinoic acid itself can restore development in these eggs when injected before incubation, especially when it is administered in the form of its methyl ester, 
which in the early stages of incubation does not possess the toxic properties of the free acid.

Our experiments show that the early chick embryo requires vitamin A. There remains from these results, however, a doubt as to whether or not there exists a period during the first 2 days of incubation in which there is no requirement for vitamin $A$. It is possible that small amounts of retinoic acid, perhaps as an ester, or small amounts of some other vitamin A-active substance, penetrate to the egg during its formation and permit the early development of the embryo. Against this theory was the finding that a majority of the embryos ceased normal development at the same stage of development, although this may be merely an indication of the time of a marked increase in the requirement for the vitamin. If the early embryo can develop to approximately stage I3 (Hamburger \& Hamilton, 195I) in the absence of vitamin $A$, this will limit the possible biochemical mechanisms involved in the mode of action of vitamin A. Also embryological and phylogenetic comparisons might suggest a specific stage in evolution at which the need for vitamin A appeared.

Another problem of general significance concerns the mechanism underlying the vitamin A requirement of the embryos beyond stage $\mathrm{I} 3$ and the relationship between the mode of action of the vitamin in these early embryos and its role in more mature birds. There is no obvious connexion between the general arrest of development of the early chick embryo and the epithelial and bone abnormalities in vitamin Adeficient chicks. The effect of deficiency on the embryo would appear to indicate a more fundamental role for the vitamin than is indicated by the manifestations of deficiency in the chick in specific tissues. In general, our observations on the effects of vitamin A deficiency on the chick embryo do not correlate well with any of the numerous theories and generalizations concerning the mode of action of vitamin $A$ that have been suggested in the past, although the participation of vitamin $A$ in the activation of sulphate (Varandani, Wolf \& Johnson, r960) might explain the defective circulation in embryos due to their inability to form cardiac jelly and blood vessels (Johnston \& Comar, 1957).

The marked differences in effects observed after direct administration to the embryo of retinoic acid, retinoic acid esters and retinol reveal relationships between chemical structure and biological properties that have not hitherto been suspected. The effect of esterification of retinoic acid in reducing toxicity and thus increasing the stimulatory effect on embryo development is especially remarkable. Esterification of retinoic acid could also be necessary for the vitamin A-like effects of retinoic acid in chicks and in other animals; free retinoic acid might be highly toxic to many growing tissues.

Our demonstration that the early chick embryo requires vitamin A suggests that the vitamin A content of practical laying diets might in some circumstances affect hatchability. The need for vitamin A during egg production however makes it unlikely that conditions will arise, without the use of retinoic acid, in which the vitamin A content of the egg will be low enough to result in the invariable early death of the embryos as occurred in our experiments. Trace quantities of retinol that would be transferred to the last few eggs from hens fed vitamin A free diets would either result 
in successful hatching or, more likely, death of embryos at late stages of incubation.

We wish to thank Professor D. L. Hughes and Professor R. A. Morton, FRS, for encouragement and advice, Mrs M. W. Harling, AIMLT, for technical assistance and Mr E. O'Neill for the photography. We also thank Hoffmann-La Roche and Co., Basel, for gifts of retinoic acid and $\beta$-apo- $8^{\prime}$-carotenoic acid, and Dr B. Morgan for the preparation of methyl-5,6-epoxyretinoate. One of us (J.N.T) was a British Egg Marketing Board Fellow and the work was supported by a grant from the British Egg Marketing Board.

\section{REFERENCES}

Almquist, H. J. \& Mecchi, E. (1939). Poult. Sci. r8, 129.

Arens, J. F. \& van Dorp, D. A. (1946). Nature, Lond. 157, 190.

Arens, J. F. \& van Dorp, D. A. (1949). Produits pharm. 4, 249.

Bohren, B. B., Carrick, C. W. \& Andrews, F. N. (1945). Rep. agric. Exp. Stn Purdue Univ. no. 37.

Briggs, G. M., Spivey, M. R., Keresztesy, J. C. \& Silverman, M. (I952). Proc. Soc. exp. Biol. Med. 8r, 113.

Cooper, D. M. (1963). Br. vet. F. I19, 194.

de Man, T. J., van Leeuwen, P. H. \& Roborgh, J. R. (1964). Nature, Lond. $201,77$.

Dowling, J. E. \& Wald, G. (1960). Proc. natn. Acad. Sci. U.S.A. 46, 587.

Elvehjem, C. A. \& Neu, V. F. (1932). F. biol. Chem. 97, 71.

Emmett, A. D. \& Peacock, G. (1923). F. biol. Chem. 56, 679.

Ferrand, R. H. \& Bohren, B. B. (1948). Poult. Sci. 27, 759.

Fox, M. R. S. \& Briggs, G. M. (1960). F. Nutr. 72, 243.

Glover, J., Goodwin, T. W. \& Morton, R. A. (1948). Biochem. F. 43, rog.

Hamburger, V. \& Hamilton, H. L. (I95I). F. Morph. 88, 49.

Hart, E. B., Steenbock, H., Lepkovsky, S. \& Halpin, J. G. (1924). F. biol. Chem. 6o, 341.

Howell, J. McC. \& Thompson, J. N. (1965). Br. F. exp. Path. 46, I8.

Howell, J. McC. \& Thompson, J. N. (1967a). Br. F. Nutr. 21, 74I.

Howell, J. McC. \& Thompson, J. N. (1967b). Br. F. exp. Path. 48, 450.

Howell, J. McC., Thompson, J. N. \& Pitt, G. A. J. (1963). J. Reprod. Fertil. 5, I 59.

Howell, J. McC., Thompson, J. N. \& Pitt, G. A. J. (I964). F. Reprod. Fertil. 7, 251 ,

Howell, J. McC., Thompson, J. N. \& Pitt, G. A. J. (1967). Br. F. Nutr. 21, 37.

Johnston, P. M. \& Comar, C. L. (1957). F. biophys. biochem. Cytol. 3, 23 I.

Jungherr, E. (I943). Bull. Storrs agric. Exp. Stn no. 250.

Krishnamurthy, S., Bieri, J. G. \& Andrews, E. L. (r963). F. Nutr. 79, 503.

Landauer, W. (196r). Monogr. Storrs agric. Exp. Stn no. I.

Lowe, J. S., Morton, R. A., Cunningham, N. F. \& Vernon, J. (I957). Biochem. F. 67, 215.

McClymont, G. L. \& Hart, L. (1948). Aust. vet. F. 24, 5.

Mason, K. E. (1939). In Sex and Internal Secretions, 2nd ed., p. i 149. [E. Allen, editor.] Baltimore: Williams and Wilkins.

Moore, T. (1953). In Symposium on Nutrition, p. 28. [R. M. Herriott, editor.] Baltimore: Johns Hopkins Press.

Moore, T. (1957). Vitamin A. Amsterdam: Elsevier.

Morgan, B. \& Thompson, J. N. (1966). Biochem. F. 101, 835 .

Robeson, C. D. (1952). U.S. Patent 2583594.

Rubin, M. \& Bird, H. R. (1942). Bull. Md agric. Exp. Stn no. A12, p. 339.

Schumacher, A. E., Scott, H. M., Hughes, J. S. \& Peterson, W. J. (1944). Poult. Sci. 23, 529.

Seifried, O. (1930). F. exp. Med. 52, 5 I9.

Seifried, O. \& Köcher, E. (1943). Z. InfektKranch. parasit. Krankh. Hyg. Haustiere 95, 32.

Thompson, J. N., Howell, J. McC. \& Pitt, G. A. J. (1964). Proc. R. Soc. B I59, 510.

Thompson, J. N., Howell, J. McC. \& Pitt, G. A. J. (1965). In Biological Council Symposium on Agents Affecting Fertility, p. 34. [C. R. Austin and J. S. Perry, editors.] London: Churchill.

Thompson, J. N., Howell, J. McC., Pitt, G. A. J. \& Houghton, C. I. (I965). Nature, Lond. $205,1006$.

Varandani, P. T., Wolf, G. \& Johnson, B. C. (1960). Biochem. biophys. Res. Comm. 3, 97.

Wagener, K. \& Harms, F. (1943). Z. InfektKrankh. parasit. Krankh. Hyg. Haustiere 95, 303.

Wald, G., Brown, P. K. \& Smith, P. H. (1953). Science, N Y. 118, 505. 
Wald, G., Brown, P. K. \& Smith, P. H. (1954-5). F. gen. Physiol. 38, 623.

Walls, G. L. (1942). The Vertebrate Eye and its Adaptive Radiation, p. 66r. Bloomfield Hills, Michigan: Cranbrook Institute of Science.

Wolbach, S. B. \& Hegsted, D. M. (1952). Archs Path. 54, 13.

\section{EXPLANATION OF PLATES}

\section{Plate I}

Sections of retina of domestic fowl, $a$ and $b$ stained with haematoxylin and eosin, $c$ stained by phosphotungstic acid haematoxylin. $A$, ganglion cell layer; $B$, inner nuclear layer, $C$, outer nuclear layer; $D$, rod-cone layer; $E$, pigment epithelium. All birds were reared on a basal diet deficient in vitamin $\mathrm{A}$, plus supplements as indicated.

(a) Bird given retinyl acetate for 222 days (group $\mathrm{IC}$ ). The retina is normal.

(b) Bird given methyl retinoate for 222 days (group $\mathrm{IB}$ ). The rod-cone layer is abnormal.

(c) Bird given methyl retinoate for $\mathbf{I} 22$ days (group IB). The rod-cone layer is abnormal but the changes are still only limited in extent.

\section{Plate 2}

Sections of testes of domestic fowl, stained by haematoxylin and eosin.

(a) Bird killed 17 days after withdrawal of methyl retinoate supplement from diet. Many spermatids have been sloughed; few mature spermatids remain.

(b) Bird given basal diet deficient in vitamin A but supplemented with methyl retinoate. Normal seminiferous epithelium; mature spermatids line the lumen. 

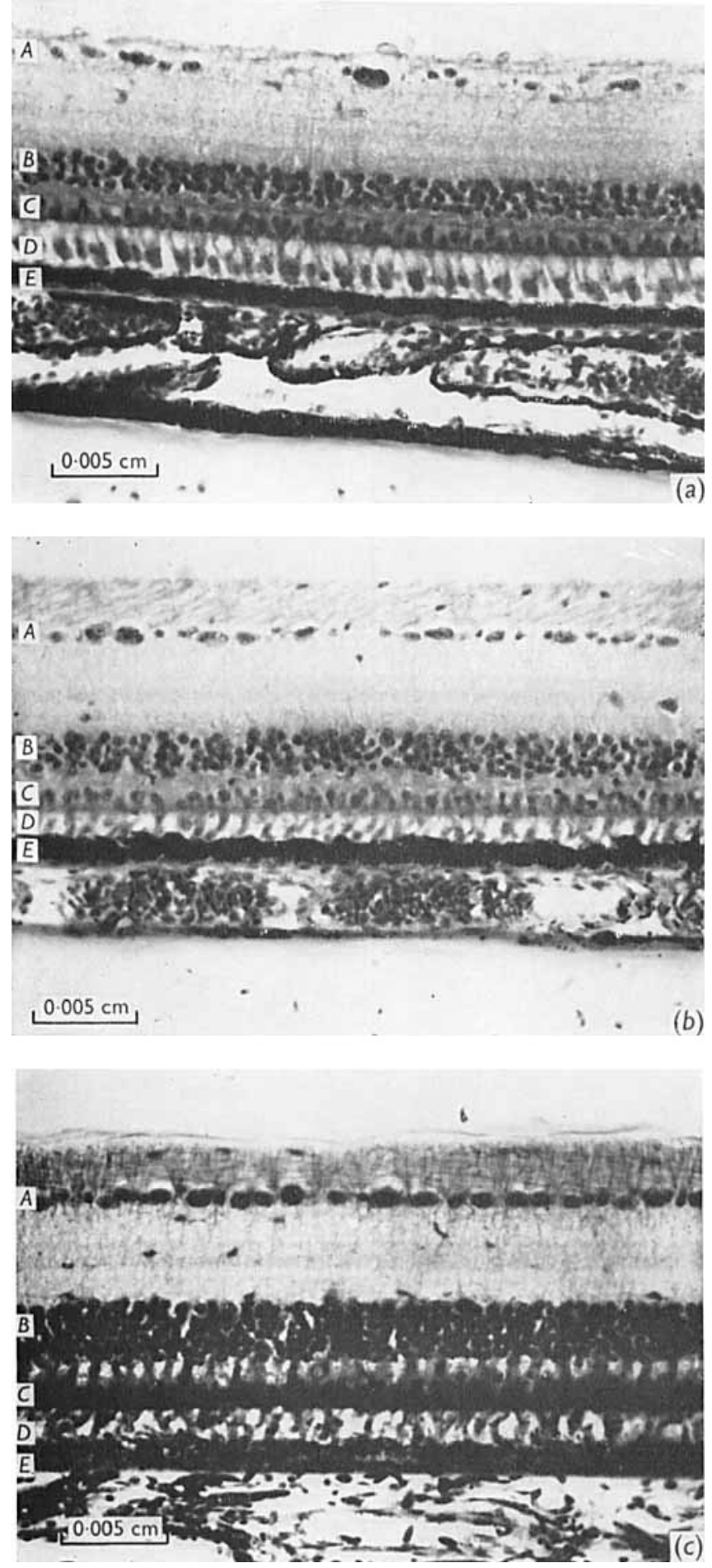

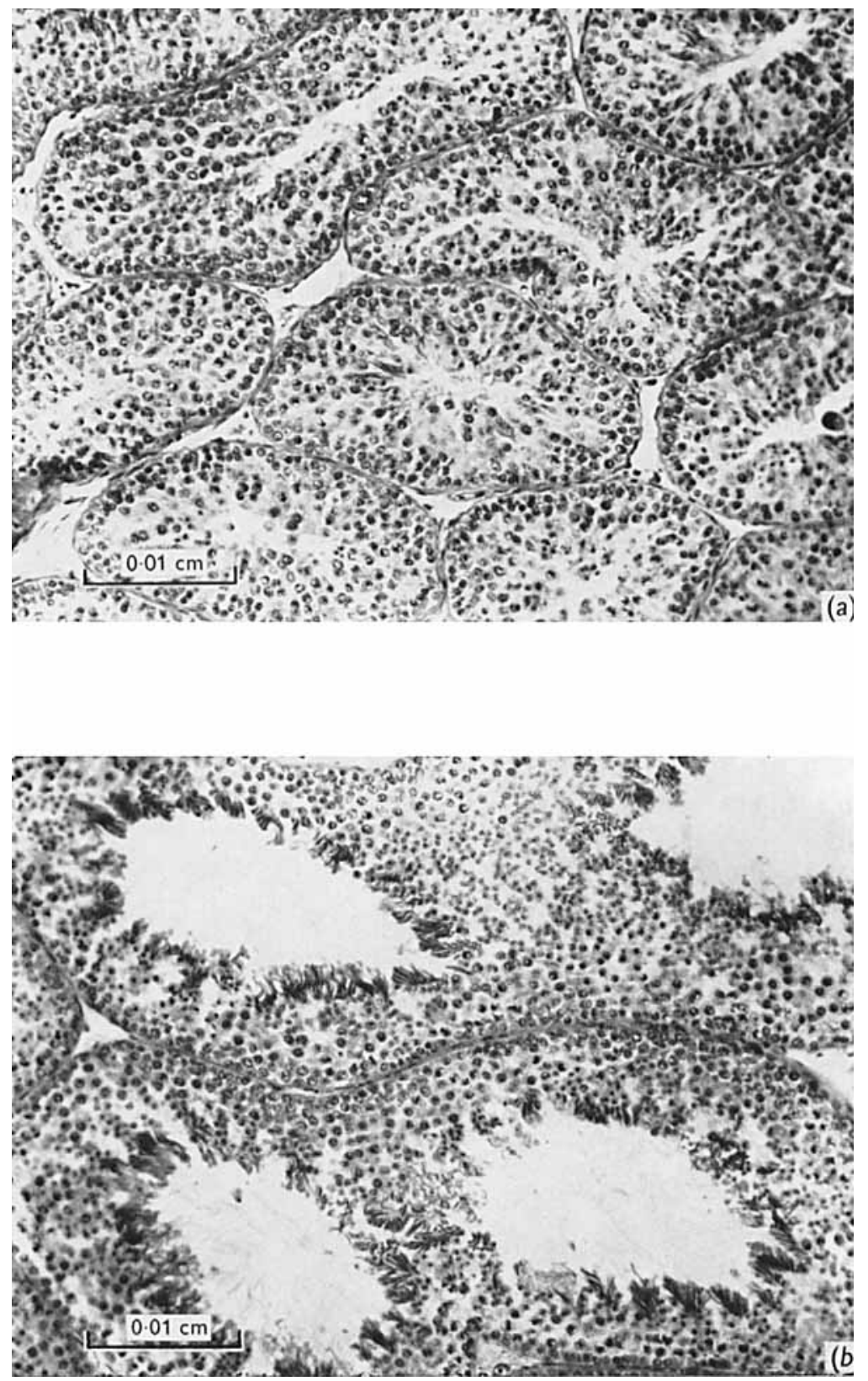

J. N. THOMPSON AND OTHERS 